\title{
A Survey on Acceptance and Readiness to Use Robot Teaching Technology Among Primary School Science Teachers
}

\author{
Laxmi Nagendra Rao ${ }^{1}$, Habibah Ab Jalil ${ }^{1}$ \\ ${ }^{1}$ Faculty of Educational Studies, Universiti Putra Malaysia, Serdang, Selangor, Malaysia \\ Correspondence: Habibah Ab Jalil, Faculty of Educational Studies, Universiti Putra Malaysia, 43400 UPM \\ Serdang, Selangor, Malaysia. Tel: 603-9769-8210. E-mail: habibahjalil@upm.edu.my
}

Received: September 3, 2021

Accepted: September 28, 2021 Online Published: October 15, 2021

doi:10.5539/ass.v17n11p115

URL: https://doi.org/10.5539/ass.v17n11p115

\begin{abstract}
Interest in educational robotics has grown in recent years, and many efforts have been undertaken across the globe to include robots into school instruction from kindergarten to high school, mostly in science and technology subjects. The current study is to determine teachers' technological acceptance and readiness to implement robotic technology in the teaching and learning process. A descriptive research design was employed which utilized a survey method. This survey was conducted among primary school teachers of Science, Mathematics, Design and Technology, and Information and Communication Technology (ICT) in Malaysia. According to the findings, teachers' acceptance of robot technology in the classroom is at a modest 3.77 ( $S D=$ $0.598)$ while the readiness score is $3.67(S D=0.611)$. The findings indicated that school teachers are only moderately prepared to employ robotic technology in classrooms. Respondents also argued that the high cost of robotic technology is a significant barrier to incorporate robotic technology into teaching and learning. The practicality of this paper is the provision of insights for exploring adoption possibilities and barriers in auguring robots into primary school classrooms. This indicates that the higher the level of teachers' acceptance, the higher teachers' readiness in robotic technology. Respondents argued that the high cost of robotic technology is a significant barrier to incorporating robotic technology into teaching and learning.
\end{abstract}

Keywords: robotics technology, teaching, affordance, acceptance, readiness

\section{Introduction}

In recent decades, the robotics industry has rapidly advanced in the permeation of human job roles, in particular, jobs that are dangerous and repetitive, such as in the field of rescue, guidance, service, and much more (Huang, 2021). Robots are also present in the education domain where they perform teaching roles. A smart educational robot is a type of learning assistance tool that can cultivate creativity, analysis, and imagination skills among various learners (Aoun, 2017). Observed among lower grade students, this robot effectively mobilizes students' initiative when it comes to teaching activities, and this is due to its characteristics of openness, intelligence, and good human-computer interaction (Bai \& $\mathrm{Li}, 2021$ ). In the practice of teaching, the educational robot is the teaching assistant to subject teachers in demonstrating the curriculum and moderating supplementary enrichment activities that boost students' attention and concentration outcomes. In tandem, this robot serves as the student's learning companion, following the concept of edutainment where students continue to learn in out-of-class domains that are enriched with student-robot interactions. Witherspoon et al. (2018) argued that robotic education fosters the development of multi-skills and knowledge at all levels of education, from preschool to university (Daniela \& Strods, 2018). In various forms, humanoid robots have been potentially useful as teaching assistants in the classroom (e.g., Conti et al., 2017; Kennedy et al., 2015; Kory-Westlund \& Breazeal, 2019). In middle school STEM classrooms, robot tutors are on-screen - specifically in a virtual reality (VR) setting, to teach general science subjects in an immersive learning environment (Makransky et al., 2019). These robots were also successful in teaching mathematics because it demonstrated rapport and engagement (Krämer et al., 2016). Therefore, a human-like pedagogical agent stimulates working memory and math skills.

Interest in educational robotics has grown in recent years, and many efforts have been undertaken across the globe to include robots into school instruction from kindergarten to high school, mostly in science and technology topics. The programmable bricks, the most recent version of educational robotic technologies, allow students to control the behavior of a tangible model through a virtual environment, allowing for new types of 
science experiments in which children investigate everyday phenomena in their lives (Resnick et al., 1996). The successful introduction of educational innovation in school settings is not just a matter of access to new technologies. Technology integration in the classroom refers to teachers' use of educational technology in the classroom, such as the use of different hardware, such as mobile technology and tablets, or software applications, such as tools, to realise particular learning processes (Mataric, 2004).

Despite its benefits, some educators still doubt their ability to implement educational robot in their teaching processes, and they struggle to adapt to new educational changes (e.g., Reich-Stiebert \& Eyssel, 2016). The underlying issue is that most educators are unaware of the reasons for the changes and the role they must play in implementing the educational robot for enhancing teaching. It is unclear as to whether the educators accept or are ready to implement teaching and learning with the support of the educational robot. In line with this reasoning, our study needs to determine the degree of readiness and acceptance among primary school teachers in terms of their attitude toward implementing teaching and learning based on the IR 4.0 robotic technology. Teachers must be trained so that they can effectively incorporate this technology into their classrooms to enhance K-12 student learning (Casey et al., 2020). The teacher training should focus on how to effectively integrate this new technology content wise, so as to allow teachers to perform practical work. The process of robotization in various fields is not new, and the first researcher to discuss the prospect utilising robotic systems for educational content was (Papert, 1984), who proposed that learners can build their numeracy skills and help the fundamental principles of physics if computers are seen in the education process and they are active participants. Later, he created the LOGO programming language and Turtle robots to enable learners to respond in the building process and learn on their own. Although educational robotics is usually linked with Science, Technology, Engineering, and Mathematics, it is not a new idea for education.

In the absence of absolute acceptance and readiness from all stakeholders, especially teachers, the novel implementation of these robots may be held back. Therefore, we highlight the importance of this study is the establishment of acceptance and readiness factors, both necessary to inform the teaching process for an engaging educational robot classroom. This study aims to identify the level of acceptance, readiness, and affordance of teachers towards the educational robot, as part of the efforts taken to implement 21 st century approach to learning in primary schools.

\section{Literature Review}

Environmentally friendly technologies are expected to change procedures in the event of a pandemic (Fernandes et al., 2020). Havenge (2020) discussed the challenges, opportunities, and insights gained from an elementary robotics program in an online environment during the COVID-19 lockdown. While students faced challenges, they were also introduced to new ways to interact online. Lessons learned from the rapid shift from full-time to online learning are used to engage students fully. The efficacy of robotic education as a therapy for children diagnosed with autism spectrum disorder is compared to traditional treatment, taking into account the requirements of unique learners (Lytridis et al., 2020). Both children and their parents are pleased with the robot-based material, according to the findings. Robots and remote-monitoring applications are examples of environmentally friendly technical equipment. The outcomes are encouraging since they successfully promote knowledge and assist providers in making decisions.

Robotic education also fosters the development of multi-skills and knowledge at all levels of education, from preschool to university (Witherspoon et al., 2018). Recently, new research directions have been developed in which it has been proven that Robotic education has such positive side effects as improved learning motivation, improved interest in learning itself, the possibility of using robotic lesson with special needs students to engage them in active learning processes, overcoming the gender gap in STEM education, and other factors that can lead to social risks (Daniela \& Strods, 2018).

Due to changes in the learning environment and technology, pedagogy, or the teaching technique, is constantly evolving (Pratama et al., 2019). The internet has altered the landscape of teaching and learning, allowing for the use of online learning resources to assist instruction. Since learning may take place on a virtual platform, face-to-face contact between the instructor and the student is no longer necessary. Because learning institutions must create employees who can deal with technology linked to IR 4.0, pedagogy is once again in need of reform in the context of IR 4.0. Robotics is presented as a self-contained learning object, it covers many educational elements and serves goals beyond those specified in the applicable curriculum, such as the development of problem-solving abilities, creativity, critical thinking, and collaboration skills, among others. Students study essential engineering, math, and computer science topics while creating and programming robots (Druin \& Hendler, 2000). Learners' research attitudes may be improved by using robotics, which allows them to establish 
hypotheses, conduct experiments, and improve their abstracting abilities. As a result, learning built via robotics (as a learning object) is equally beneficial for other cognitive domains throughout the school curriculum.

Several educational programmers and initiatives involving universities, schools, and other educational and research organizations have been established in the area during the past several years. A representative selection of them is briefly given in the following lines to give an idea of the diversity of subject areas, educational goals, learning methods, themes, and different audiences engaged in previous and current robotics applications in wider classroom contexts.

\section{Materials and Methods}

This study used the quantitative method to evaluate the level of affordance, acceptance, and readiness of primary school teachers in adopting robotic teaching technology in science classrooms. A questionnaire was developed as the method for data collection. The simple random sampling technique was used to select the respondents. The respondents of this study were 296 primary school teachers in the state of Malacca, under the district of Alor Gajah. Although the study is restricted to Alor Gajah, Malacca teachers, the findings are expected to shed light on teachers' knowledge and skills in robotic technology, and attitudes and obstacles they face when implementing it in the classroom. This study is important because it ties to schools. If the study's survey yields positive results, the school can give relevant courses to help teachers become skilled in integrating Robotic technology in the teaching and learning process. Moreover, the MOE can use the survey's findings to develop robotics courses. At the same time, the Malaysian Ministry of Education can use the findings to update its curriculum.

For data collection, the questionnaire was developed and adapted from Wang et al. (2019) to encompass robotics technology contexts. The instrument measurement is a 5-point Likert scale because the finer 5-point scale enables respondents to figure out items in a manner closer to the structural pattern of the size, leading to higher reliability and validity. The first part sought respondents' demographic information, such as gender, age, job function, working experience, subject taught, type of school, and school location. The second part is teachers' technology affordance in terms of their knowledge level. The third and fourth parts sought teachers' acceptance and readiness in implementing while the fifth part gauged the respondents' perception of possible implementation challenges of incorporating robotics technology in the teaching and learning process in a science classroom. According to Kombo and Tromp (2006), a pilot study is necessary to validate and confirm the reliability of the research instrument. Therefore, this study piloted the research instrument by randomly selecting 30 science teachers of another state. This served to measure how well the research instrument measures what it was created to measure. Following Streiner's (2020) views, all the items of the instrument were adapted from a scholar. To guarantee instrument validity, we sought a scholarly expert with a professorship tenure in the field for validation. The research instrument was piloted after which modifications were made to suit the content validity of the instrument.

\section{Results and Discussion}

According to the findings, the mean value for acceptance is $3.77(S D=0.598)$ while readiness is $3.67(S D=$ $0.611)$. Finally, the mean for a teacher's technological challenge is $3.17(S D=0.241)$. Table 1 proves that the majority of the respondents choose to agree to the first item in performance expectancy which is "I would find the technology in teaching and learning is useful." The findings support the opinions of Roy (2019) who believes that technique is useful in teaching and learning in order to make language learning easier for their students. The second item in performance expectancy is "Using the technology in teaching and learning enables me to accomplish tasks more quickly." In this item, $60.6 \%$ of respondents viewed that robotics technology enables them to finish their task more quickly. Furthermore, almost $17 \%$ of respondents agreed that using this technology in teaching and learning enhances teacher productivity.

In the context of effort expectancy, $65 \%$ of respondents agreed with the statement that their interaction with this technology in teaching and learning would be clear and understandable. The findings also indicated that $59 \%$ and $53 \%$ of respondents respectively thought that by adopting this technology, they would rapidly become skilled at it, and that using it in teaching and learning would be easy for them. As a result, the teachers have positive perceptions on the adoption of this technology. To measure the dimension of social influence, four items were included in the questionnaire. However, only two items were identified based on their high mean. As displayed in the findings, the respondents professed that they would adopt the technology if their colleagues would. This shows that the level of respondents' willingness for robotics technology adoption is influenced by their peers. Therefore, this social influence item explains that teachers' source of inspiration comes from their professional peers when it comes to accepting and applying new technologies in the teaching and learning process. 
To measure teachers' readiness in robotics technology, three items of behavioral intention were used. The first item is "I intend to use robotics technology in my teaching and learning in the upcoming months." As shown in Table 2, 47\% of respondents expressed their intention to use robotics technology in their teaching in the upcoming months. $64 \%$ of school teachers would use this technology in my teaching in the upcoming months. These findings on science teachers' acceptance and readiness show moderate acceptance for robotics technology in classrooms.

Table 1. Descriptive statistics of teachers' acceptance to use robotic technology.

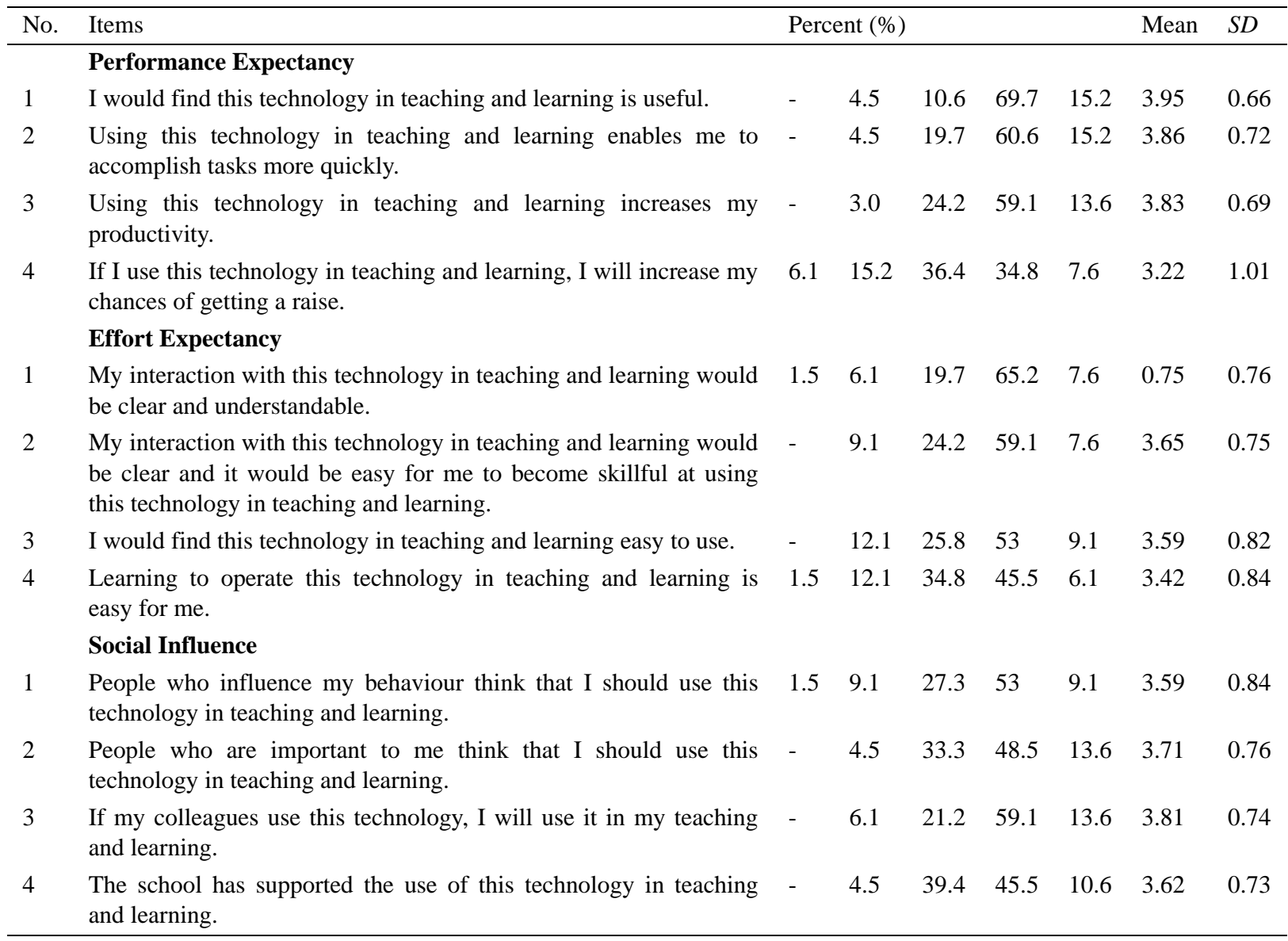

Table 2. Descriptive statistics of teachers' readiness to use robotic technology.

\begin{tabular}{llllllllll}
\hline No. & Items & Percent $(\%)$ & & & Mean & SD \\
\hline 1 & $\begin{array}{l}\text { Behavioural Intention } \\
\text { I intend to use this technology in my teaching and learning in the }\end{array}$ & 1.5 & 9.1 & 30.3 & 47 & 12.1 & 3.59 & 0.87 \\
& $\begin{array}{l}\text { upcoming months. } \\
\text { I expect I would use this technology in my teaching and learning in } \\
\text { the upcoming months. }\end{array}$ & 3 & 7.6 & 42.4 & 36.4 & 10.6 & 3.43 & 0.89 \\
3 & $\begin{array}{l}\text { I plan to use this technology in my teaching and learning in the } \\
\text { upcoming months. }\end{array}$ & 3 & 10.6 & 42.4 & 34.8 & 9.2 & 3.36 & 0.90 \\
\hline
\end{tabular}

Finally, the current study also presents common challenges faced by teachers when attempting to integrate the technology in teaching science in primary school classrooms. Five items were utilised to assess the challenges of the technological bottleneck, a shortage of talent, morality and ethics, high costs, and lastly the idea and awareness of robotics technology. Only 66 respondents responded to this part. The results displayed that the highest mean of the main challenge in robotics technology is robotics technology concepts and awareness which is 3.9839 . Secondly, the mean of the morality and ethics challenge in robotics technology is 3.5645 , followed by 
the challenge of costs, which is 2.8548 . This is followed by the challenge of the lack of talent which scored a mean of 2.5645. Finally, the lowest challenge ranked was the technical bottleneck of robotics technology which is 2.0323 .

\section{Conclusion and Implications}

Since primary school science teachers' perceptions of robotic teaching technology are moderate, more efforts by schools and teachers are required to improve robotics usage. The study also found that most teachers agree that technology will improve their teaching. Also, most teachers are expected to use technology positively and easily. They agreed that social influence would help them confidently use robotics in education. These include investing in robotics technology and learning about it on one's own. Using robotics in primary science classes helps students develop communication and teamwork skills, which are important technological affordances for IR 4. Science teachers will be excited to experience the ease of teaching once they see how robotics technology can inspire science curriculum and stimulate lesson delivery. To begin, most respondents think robotic technology in education is valuable. Roy (2019) claims that teaching and learning techniques can help students learn languages more easily. As IR 4 approaches, it is important for primary school science teachers to accept technology in their classrooms. Even respondents believe that teachers' interactions with IR 4 technologies would be clear and understandable. According to the study, teachers' teaching and learning will be more understandable if robotic technologies are accepted. This attitude of acceptance is much needed as the teaching community must continue to evolve, moving away from archaic teaching methods and techniques towards contemporary ones. Therefore, it is important that the science teaching community at primary school level realize the benefits of robotics technology, that is it is compatible and manageable in classrooms. Policy makers appear convinced that robotics technology is essential if teachers are reasonably prepared to face the challenges of the borderless world. It is undeniable then that robotics technology has become a potent production tool and it offers exciting approaches to teaching, and if this technology is used extensively, and in proper manner, it could bring exponential improvement in education.

New technology enhancing or driving existing traditional learning, Gagne (2005) says. Robotics can help fill in educational media holes (Norabeerah, 2011). This study evaluated teachers' ability, acceptance, and readiness to use robotics. 74 teachers from Alor Gajah district were studied. 19 male and 55 female teachers. This feedback should be fed to the government for further action. Schools can be more responsive to teacher suggestions and requests if they are open-minded. This can be accomplished by enrolling teachers in courses on educational technology.

This workshop can prepare teachers for IR 4. Robotics can make learning more fun for students. The books were updated to allow for two-way communication. This may not be possible if teachers do not choose to integrate changes. Define future robotic technology capability, readiness, and acceptance. Teachers are willing to use new technology if properly trained and equipped. They've all heard of but never used this tech. Saltan and Arslan say it's available but rarely used in schools (2017).

\section{Limitations of the Study and Implications for Future Research}

The Ministry of Education should hold numerous seminars and in-house sessions to improve teaching and learning using robotic technology. IR 4 requires training for teachers from early childhood to secondary, according to regional feedback. Participants may also be given tools such as 3D printers, 3D pens, VR boxes, and AR glasses to better understand technology affordances. Although costly, it can be beneficial to teachers for future use.

This path would also be linked to social change, knowledge dissemination, and technological awareness. Also, a qualitative method, in addition to the quantitative method, would be added so that more information can be gathered on the relationship between technology affordance, acceptance, and readiness among primary school teachers in integrating IR 4 . The teacher training program on robotics technology for education received positive response on its content and structure. This encouraged our research team to incorporate constructivist learning approaches and project-based learning in future training programs. Having said that, we recommend that future training and pairwise comparisons of this training program include the following recommendations, some of which are omitted.

I. Added training sessions could be inserted into the training program to make it more comprehensive. The training's extension could improve participants' acceptance, self-efficacy, and perceptions.

II. Comprehension and activities with additional educational robotics technology and programming resources can be included in the training program. It could, for example, include sessions with other school-appropriate 
resources such as Scratch Jr (Papadakis et al., 2017), KIBO (Bers \& Donohue, 2019), RoboTito (Gerosa et al., 2019), and Bee-bot (Di Lieto et al., 2017).

III. More opportunities should be provided to participants to experiment with educational robotics resources and teaching materials. This would allow participants to feel more at ease and confident with the resources, as well as enjoy the learning process without feeling hurried, which could have a positive effect on their acceptance, self-efficacy, and perceptions.

IV. A larger sample size, one that is larger than 300 , would inform better implementation of this study as this increases instrument and scale reliability. This sample could allow confirmation and assumption development of the positive results, and a structural equation study can be conducted.

Despite various recommendations, the university teaching advisory board should emphasize the implications of robotics education in teacher education and implement effective reforms to incorporate robotics training into teacher education.

\section{Acknowledgements}

The authors gratefully acknowledge the funding provided by the Malaysian Ministry of Higher Education's Research University Network Grant (UPM/800-4/11/MRUN/2018/5539210); and the support from Innovative Learning Sciences Research Centre of Excellence (INNOVATE), UPM.

\section{References}

Aoun, J. E. (2017). Robot-proof: Higher education in the age of artificial intelligence. MIT press. https://doi.org/10.7551/mitpress/11456.001.0001

Bai, X., \& Li, J. (2021). Applied research of knowledge in the field of artificial intelligence in the intelligent retrieval of teaching resources. Scientific Programming, 2021, 1-11. https://doi.org/10.1155/2021/9924435

Bers, M. U., \& Donohue, C. (2019). Coding as another language: Why computer science in early childhood should not be STEM. In Exploring Key Issues in Early Childhood and Technology (pp. 63-70). Routledge. https://doi.org/10.4324/9780429457425-11

Casey, J. E., Pennington, L. K., \& Mireles, S. V. (2020). Technology acceptance model: Assessing preservice teachers' acceptance of floor-robots as a useful pedagogical tool. Technology, Knowledge and Learning, 26, 1-16. https://doi.org/10.1007/s10758-020-09452-8

Conti, D., Di Nuovo, S., Buono, S., \& Di Nuovo, A. (2017). Robots in education and care of children with developmental disabilities: A study on acceptance by experienced and future professionals. International Journal of Social Robotics, 9(1), 51-62. https://doi.org/10.1007/s12369-016-0359-6

Daniela, L., \& Strods, R. (2018). Robot as agent in reducing risks of early school leaving. In L. Daniela (Ed.), Innovations, technologies and research in education (pp. 140-158). Cambridge Scholars Publishing.

Di Lieto, M. C., Inguaggiato, E., Castro, E., Cecchi, F., Cioni, G., Dell'Omo, M., ... Sgandurra, G. (2017). Educational Robotics intervention on Executive Functions in preschool children: A pilot study. Computers in Human Behavior, 71, 16-23. https://doi.org/10.1016/j.chb.2017.01.018

Gerosa, A., Koleszar, V., Gómez-Sena, L., Tejera, G., \& Carboni, A. (2019). Educational robotics and computational thinking development in preschool. 2019 XIV Latin American Conference on Learning Technologies (LACLO), 226-230. https://doi.org/10.1109/LACLO49268.2019.00046

Huang, S. (2021). Design and development of educational robot teaching resources using artificial intelligence technology. International Journal of Emerging Technologies in Learning, 15(5), 116-129. https://doi.org/10.3991/ijet.v16i05.20311

Kennedy, J., Baxter, P., \& Belpaeme, T. (2015). The robot who tried too hard: Social behaviour of a robot tutor can negatively affect child learning. 2015 10th ACM/IEEE International Conference on Human-Robot Interaction (HRI), 67-74. https://doi.org/10.1145/2696454.2696457

Kombo, D. K., \& Tromp, D. L. (2006). Proposal and thesis writing: An introduction. Nairobi: Paulines Publications Africa, 5(1), 814-830.

Kory-Westlund, J. M., \& Breazeal, C. (2019). A long-term study of young children's rapport, social emulation, and language learning with a peer-like robot playmate in preschool. Frontiers in Robotics and AI, 6, 1-17. https://doi.org/10.3389/frobt.2019.00081

Krämer, N. C., Karacora, B., Lucas, G., Dehghani, M., Rüther, G., \& Gratch, J. (2016). Closing the gender gap in 
STEM with friendly male instructors? On the effects of rapport behavior and gender of a virtual agent in an instructional interaction. Computers \& Education, 99, 1-13. https://doi.org/10.1016/j.compedu.2016.04.002

Makransky, G., Wismer, P., \& Mayer, R. E. (2019). A gender matching effect in learning with pedagogical agents in an immersive virtual reality science simulation. Journal of Computer Assisted Learning, 35(3), 349-358. https://doi.org/10.1111/jcal.12335

Papadakis, S., Kalogiannakis, M., \& Zaranis, N. (2017). Improving mathematics teaching in kindergarten with realistic mathematical education. Early Childhood Education Journal, 45(3), 1-11. https://doi.org/10.1007/s10643-015-0768-4

Reich-Stiebert, N., \& Eyssel, F. (2016). Robots in the classroom: What teachers think about teaching and learning with education robots. In A. Agah, J. J. Cabibihan, A. Howard, M. Salichs, \& H. He (Eds.), International conference on social robotics (Vol. 9979, pp. 671-680). Springer. https://doi.org/10.1007/978-3-319-47437-3_66

Roy, A. (2019). Technology in Teaching and Learning. Journal of Emerging Technologies and Innovative Research (JETIR), 6(4), 356-362. https://doi.org/10.31686/ijier.vol7.iss4.1433

Streiner, D. L. (2020). 10 Figuring Out Factors: The use and misuse of Factor Analysis. In D. L. Streiner \& Canadian Psychiatric Association (Eds.), A Guide for the Statistically Perplexed (pp. 110-122). University of Toronto Press. https://doi.org/10.3138/9781442662827-012

Wang, L., Iocchi, L., Marrella, A., \& Nardi, D. (2019). Developing a questionnaire to evaluate customers' Perception in the Smart City Robotic Challenge. 2019 28th IEEE International Conference on Robot and Human Interactive Communication (RO-MAN), 1-6. https://doi.org/10.1109/RO-MAN46459.2019.8956394

Witherspoon, E. B., Schunn, C. D., Higashi, R. M., \& Shoop, R. (2018). Attending to structural programming features predicts differences in learning and motivation. Journal of Computer Assisted Learning, 34(2), 115-128. https://doi.org/10.1111/jcal.12219

\section{Copyrights}

Copyright for this article is retained by the author(s), with first publication rights granted to the journal.

This is an open-access article distributed under the terms and conditions of the Creative Commons Attribution license (http://creativecommons.org/licenses/by/4.0/). 